\title{
Characteristics of the Yihe River Paleo-Valley near the Linyi Jiuqu Yihe River Bridge, Shandong Province
}

\author{
Ting $\mathrm{Wu}^{1, \mathrm{a}}$, Kechao Yan ${ }^{1, \mathrm{~b}}$ and Guangjie Cao ${ }^{2, \mathrm{c}}$ \\ ${ }^{1}$ School of Population, Resources and Environment, Shandong Normal University, Jinan 250014, \\ China; \\ ${ }^{2}$ School of Resources \& Environment, Linyi University, Linyi 276005, China; \\ a wuting90730@163.com, b yankechao@lyu.edu.cn, ${ }^{c}$ guangjiecao@163.com
}

Keywords: The Jiuqu Yihe River Bridge, the paleo-vallye, the last glacial maximum, the late glacial.

\begin{abstract}
The Yihe River's stratigraphical cross-section near the Jiuqu Yihe River Bridge of Linyi City was selected as the research zone. The stratigraphical cross-sections of paleo-valley were established with bore datum near the Jiuqu Yihe River Bridge. The geophysical seismic imaging method of shallow stratigraphy was applied to detect drilling. Data of 1 OSL dating was obtained through the analysis of the sample collected from the bottom of the paleo-valley near the G327 Yihe River Bridge and of $2{ }^{14} \mathrm{C}$ dating were obtained through the analysis of the samples collected in burial terrace of the Benghe River. It is concluded that: the Yihe River paleo-valley is located on the fault zone. Near the Jiuqu Yi River Bridge, the paleo-valley below 53 55m is the paleo-valley of the Yihe River and Benghe River in the Last Glacial Maximum (LGM). During the LGM, the Benghe River flowed into the Yihe River in the downstream of the Jiuqu Yihe River Bridge. The paleo-valley above $54 \mathrm{~m}$ is considered as the paleo-valley of the Yihe River since the LGM. After the Late Glacial, the Benghe River flowed into the Yihe River at the present location. The Yihe River paleo-valley has a relatively large width-depth ratio, which means a wide and shallow river channel with the characteristics of braided river.
\end{abstract}

\section{Introduction}

The environment of the last glacial has long been a hot research at home and abroad. Research on hydrology and water cycle is the important area of studying the past environmental changes. The study of paleochannel plays a significant role in the research of past water cycle. It helps to understand the evolutionary history of the fluvial geomorphology in an area and also functions as an important method of studying paleogeographic environment. Therefore, the study of paleochannel has attracted more and more attention of scholars. Domestic researches on paleochannel in the last glacial period mostly concentrate on large rivers. The Yangtze River's flowing route into the sea during the last glacial maximum and buried paleochannel has been discussed by many scholars [1-12]. Zhang Zulu [13], Wu Chen [14,15] and others have studied the buried paleochannel in the North China Plane. Some researchers have also studied the paleochannels of the Pearl River [16], the Qiantang River [17], the Huaihe River [18] and so on. However, the researches on the paleochannels of regional rivers which do not directly flow into the sea are very few. The paleochannel of the Yihe River has not yet been researched by scholars at present. Yihe River, located in the climatic transition zone and the sensitive area of climatic change in East Asian Monsoon Region, is an important tributary of the Huaihe River. The research on the paleochannel of the Yihe River during the last glacial period will provide important clues for discussing the paleohydrology and paleoenvironment of the North China monsoon region in the last glacial stage.

The key to the study of paleochannel is to determine the age of stratum. However, to collect the appropriate and representative dating samples is very difficult. Besides, often due to technical limitations and the not enough concentration of sampling points in the same place, the resolution of research is relatively low. This study collected the dating samples of the Yihe River's paleochannel on the typical section, which made the samples have certain representativeness. In addition, dense 
drilling was conducted by using geological exploration drilling technology and the geophysical seismic imaging method of shallow stratigraphy was also applied along the drillholes. For these reasons, the resolution of the research was improved greatly.

The Yihe River originates from the southern foot of Mountain Lu in Yiyuan County, Shandong Province. It flows south into Yiyuan, Yishui, Yinan, Linyi and Tancheng, entering the territory of Jiangsu Province in the south of Tancheng. After entering the Northern Jiangsu Plain, parts of it flow into the Yellow Sea by Guanhe estuary, parts infuse into Luoma Lake and interlink with the Huaihe River via Beijing-Hangzhou Grand Canal. Yihe River is $574 \mathrm{~km}$ in total length with the basin area of $17325 \mathrm{~km}^{2}$ and is $280 \mathrm{~km}$ of length, $9383 \mathrm{~km}^{2}$ of basin area in Shandong Province. The upstream of the Yihe River is from the source to Bashan Reservoir, the midstream ranges from Bashan Reservoir to the Benghe River estuary and below the Benghe River estuary is the downstream. The Benghe River is the largest tributary of the Yihe River and runs into the Yihe River in the northeast of Linyi city. The Jiuqu Yihe River Bridge of Linyi is located in $1.5 \mathrm{~km}$ below the downstream of the place where the Benghe River flows into the Yihe River (see Figure1). The river reach will have a certain representational significance in studying the paleochannel of the Yihe River, for this reason, it was selected as the research object.

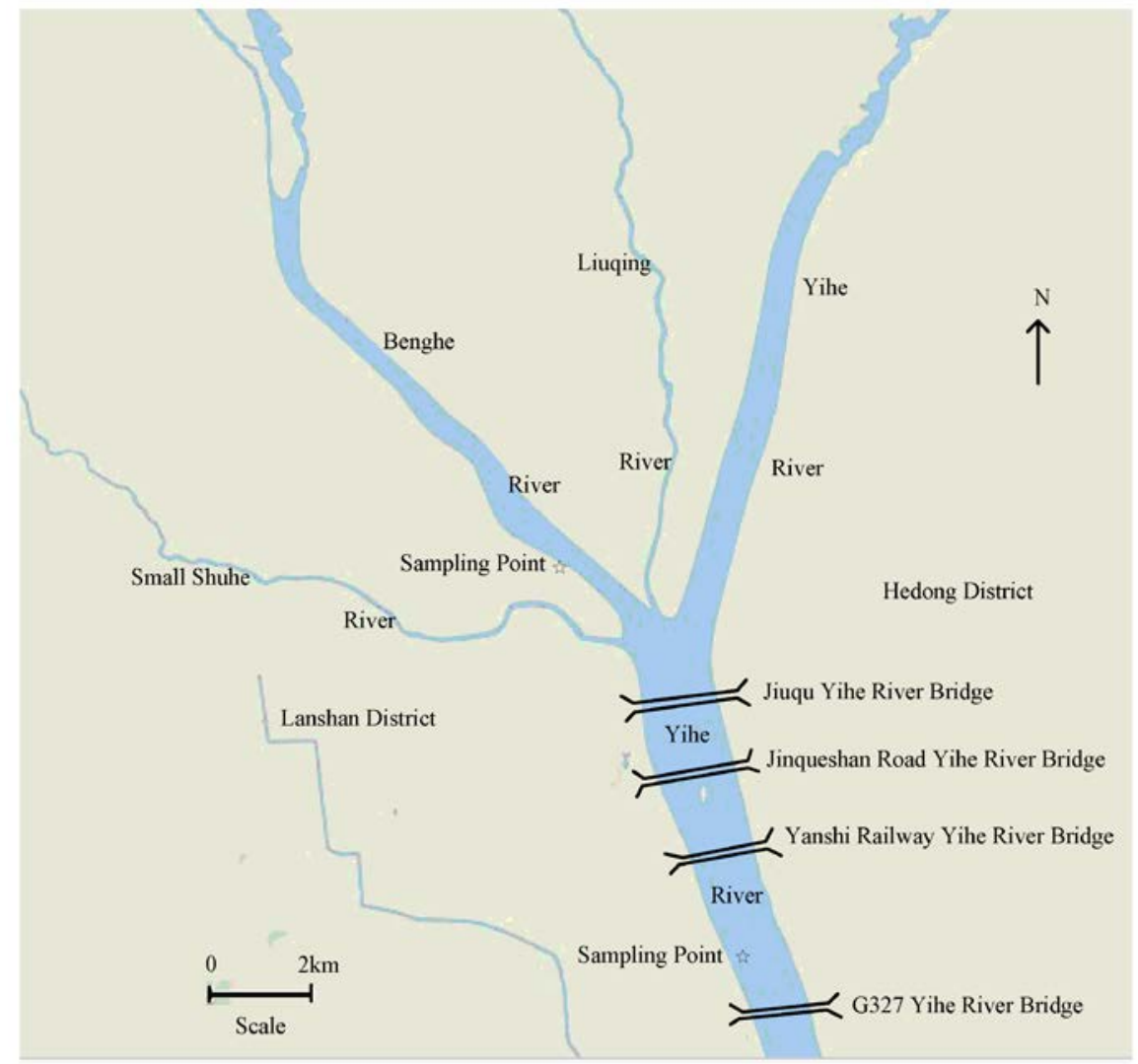

Fig. 1 Location of the Stratigraphical cross-section near the Jiuqu Yihe River bridges at Linyi

\section{Materials and Methods}

Drilling Data Analysis and Sample Collection. 162 geological prospecting boreholes near the Jiuqu Yihe River Bridge of Linyi were collected and sorted out. 72 boreholes on the same straight line direction were selected. According to the distance between the boreholes and drilling depth, the horizontal scale and vertical scale were separately determined. On the basis of the above scale, the stratigraphical cross-section of paleo-valley near the Jiuqu Yihe River Bridge was established. Finally, the schematic diagram of stratigraphical cross-section was drawn successfully through Mapinfo software.

Combined with engineering mining, 1 sample for OSL dating was collected in the grit-gravel bed lying at the bottom of the Yihe riverbed near the G327 Yihe River Bridge which is located in the downstream of the Jiuqu Yihe River Bridge. 2 samples for ${ }^{14} \mathrm{C}$ dating were collected in the floodplain 
sediments of the burial terrace lying on the right bank of the Benghe River, $3 \mathrm{~km}$ distance from the downstream of the Jiuqu Yihe River Bridge.

The Geophysical Seismic Imaging Method of Shallow Stratigraphy. Seismic imaging method, receiving seismic signal by progressively moving the measuring point based on the same small offset distance, is a method of shallow seismic exploration that continuously scans on the ground for the shallow stratigraphy or underground target and then detects subterranean medium changes by using plenty of information about seismic waves. At the surface, the seismic waves propagate down under the condition of artificial stimulation, when they face with the interface of different elastic medium, they will generate reflection, refraction and projection. Due to the transformation received from subsurface stratigraphic medium during reception, the seismic waves that are recorded via the high precision seismograph will bring all kinds of information related to the geological structure, stratum lithologic characters and so on, such as time, speed, energy, phase position, frequency and other abnormal changes. The information abstracted from the seismic records is carried through such data processing as the noise reduction of signal superposition, velocity analysis, spectral analysis, filter analysis, NMO correction, CDP superposition, smoke channel synthesis and picture synthesis in accordance with different exploration goals in order to obtain the underground two-dimensional images. The shapes of geological structure, the distribution of special geological bodies and others, can be inferred from the interpretation and explanation of the images. The Quaternary overburden near the Jiuqu Yihe River Bridge of Linyi is relatively shallow, and the mantle includes silty clay, medium-coarse sand, cobble, etc. The difference of wave impedance and wave velocity with buried bed rock is obvious, as there are bedding planes with different physical properties, reflecting interface could be formed. Therefore, it can be detected by the geophysical seismic imaging method of shallow stratigraphy.

The instruments used for seismic exploration are the Changsha GJY-1A type engineering detector and the seismograph developed by Jin Da technical services, Xi'an geological instrument factory production of $100 \mathrm{~Hz}$ detector. CSP3.0, CSP5.0, RWS and other seismic processing software are used. The earthquake origin is 24 pounds of hammer, $100 \mathrm{~Hz}$ of detector, $2 \mathrm{~m}$ of track pitch, $4 \mathrm{~m}$ of minimum offset distance, $1 \mathrm{~m}$ of shot interval, $0.5 \mathrm{~ms}$ of sampling interval, and 512 sampling points. Small offset distance image method is applied in the earthquake. It begins from about holes K15-K45 (see Figure2), accomplishing 2 southern and northern profiles, about $800 \mathrm{~m}$, 4800 physical points.

Sampled data of seismic section is processed as the optimal image in the computer. Different offsets reflect different seismic depth information. Abnormal changes in amplitude energy of seismic wave, the embranchment, recombination, dislocation and distortion of seismic event, cycle changing, and waveform deformation reflect the geological characteristics of structures, cracks, weak intercalated layer and so on, with very obvious effect.

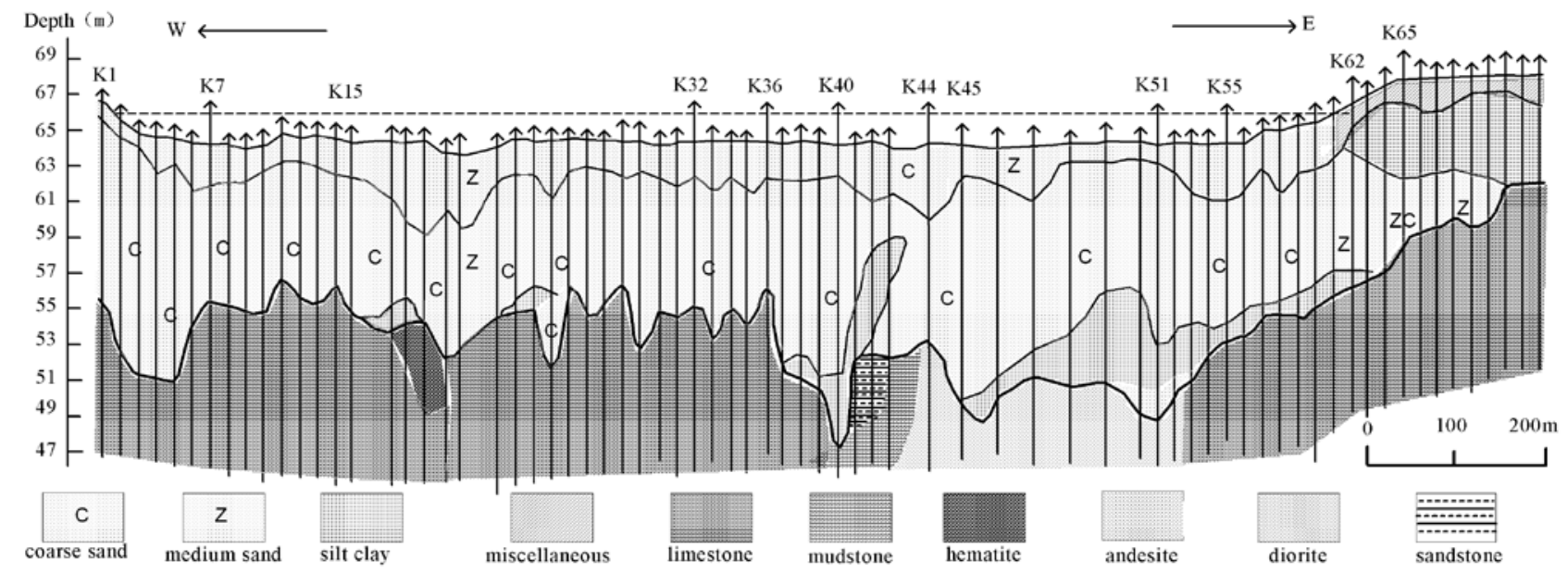

Fig.2 The stratigraphical cross-section of the Yihe River incised-valley near the Jiuqu Yihe River 


\section{Result}

The stratigraphical cross-section near the Jiuqu Yihe River Bridge. Figure 2 is the stratigraphical cross-section of the Yihe River paleo-valley based on geological exploration and drilling data near the Jiuqu Yihe River Bridge. Boreholes reveal that near the Jiuqu Yihe River Bridge, the paleo-valley is down to the bottom of now riverbed; holes K1-K7, holes K36-k41 and holes K44-K55 are a set of relatively deep troughs and in about $53 \mathrm{~m}-55 \mathrm{~m}$ is burial terrace. The bottom of the river channel cuts into the weakly weathered limestone, weathered mudstone, strongly weathered sandstone, strong weathering andesite, etc. The lithology is more complex, and there are fault zones and cracks. The sediment at the bottom of the deep channel between holes K1-K7 is isabelline coarse sand, which is medium dense, saturated, and generally sorted. The main ingredients are quartz and feldspar, occasional a little round gravel and some pebbles with good grinding roundness. The deepest point of hole $\mathrm{K} 4$ reaches bedrock is at the depth of $50.98 \mathrm{~m}$, and hole $\mathrm{K} 1$ is at $55.13 \mathrm{~m}$. The depth of the river channel between holes K1-K7 is about $4.15 \mathrm{~m}$, the width is $120 \mathrm{~m}$ and the width-depth ratio is 28.92; the deposit of the deep channel's bottom between holes K36-K41 is tawny sandy clay, which has strong plasticity, occasional stratification structure and a little gravel over the upper part. The deepest spot of hole K40 reaches bedrock is at $47.26 \mathrm{~m}$, and hole $\mathrm{K} 41$ is at $52.24 \mathrm{~m}$. The trough depth of the river channel between K36-K41 holes is about $4.98 \mathrm{~m}$, the trough width is about $80 \mathrm{~m}$, and the ratio of width to depth is 16.06 ; from hole $\mathrm{K} 44$ to hole $\mathrm{K} 55$, the bottom of the river channel in holes K49-K53 deposits isabelline coarse sand, which is medium dense, saturated and has ordinary sorting feature. Its main ingredients are quartz and feldspar, and a small amount of round gravel and few pebbles, with good psephicity. Other parts deposit tawny silty clay which is plastic and contains many sands and a small number of pebbles. The deepest place of hole K51 reaches bedrock is at $48.68 \mathrm{~m}$, and hole $\mathrm{K} 44$ and hole $\mathrm{K} 55$ both reach bedrock at $53.33 \mathrm{~m}$, the depth of the river channel between holes K44-K55 is about $4.65 \mathrm{~m}$, the trough width is about $340 \mathrm{~m}$, and the proportion between width and depth is about 73.12 .

It is basically tan coarse sand deposited in the whole river channel above about $54 \mathrm{~m}$. Its density is medium, saturability is good and sorting feature is common. The main components are quartz and feldspar, plus few pebbles. There is burial terrace in about $59 \mathrm{~m}$, and hole K65 reaches bedrock at $59.01 \mathrm{~m}$. The depth of the river channel is about $5 \mathrm{~m}$, and the breadth of continuous tawny coarse sand sediments is about $1460 \mathrm{~m}$. The width to depth ratio of the valley in this period is about 292 . The east bottom of the current river bed has deposition of about 4 9m thick tan medium sand, slightly-medium dense, saturated, and normally sorted. Its lower part has gravel-cobbles, which has a good psephicity. The upper part has deposited tawny silty clay with the thickness of $5 \sim 7 \mathrm{~m}$, the plastic is strong and the soil texture is homogeneous. On the uppermost part is the miscellaneous fill with the thickness of $1 \mathrm{~m}$.

The result of seismic geophysical cross-section. The seismic section image has reflected the location and characteristics of fault fracture zone clearly. In Figure 3, approximately starting from $\mathrm{K} 36$, there is a downtrend in lineup, accompanied by offset. It reaches the lowest point near K40 and begins to rise. The rising trend of lineup ends near K42. It is speculated that paleo-valley is between K36-K42. The transformation of waveform in this place, etc., reflect the structure fracture, and the distribution of fault can be deduced to be between K38-K43, with width of $80 \mathrm{~m}$, north trend and west tendency. There is a crack in K32-K34 and corrosion phenomenon in the shallow part, with north trend and west tendency. There is also a crack in K43-K44 with north trend and west tendency. 


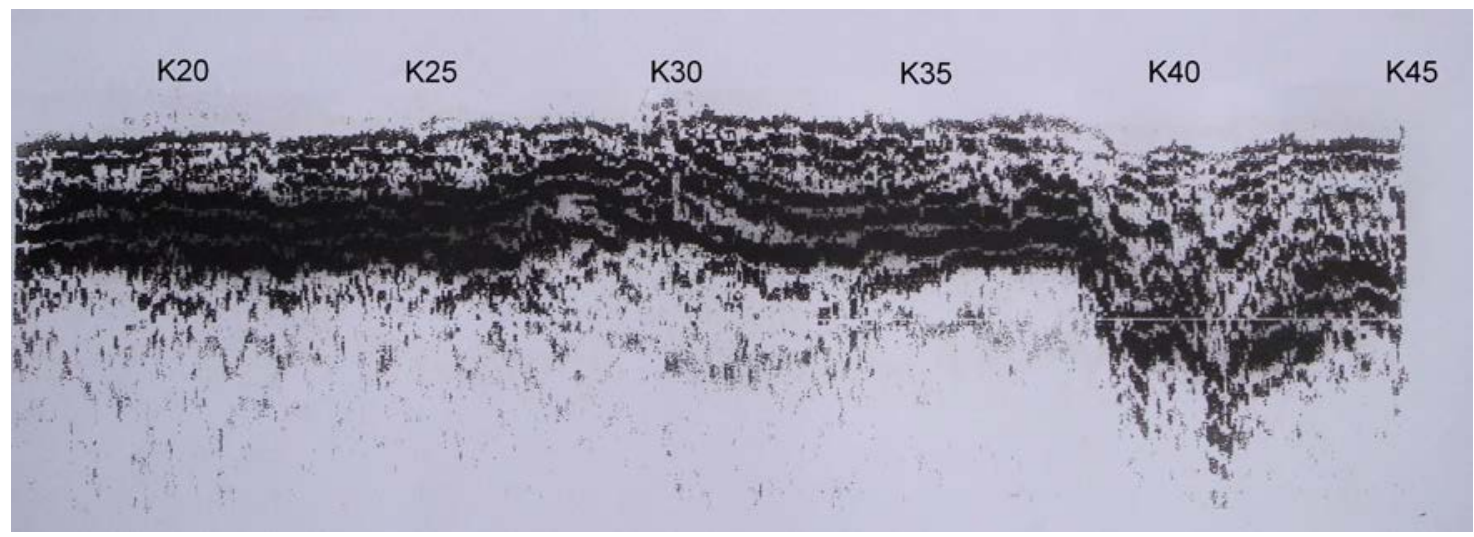

Fig.3 Seismic section image near the Jiuqu Yihe River bridge of Linyi

\section{Discussion}

As the boreholes reveal, among the holes K38-K43 near the Jiuqu Yihe River Bridge, burial bedrock are made up of mudrock, sandstone and limestone with complicated lithologic characters. And it is fracture zone owning to the development of fracture and crack. The seismic section image also clearly reflects that there exists fracture zone between holes K38-K43, with a width of about 80m; the boreholes reveal that the burial bedrock between holes K43-K44 are respectively mudstone and andesite; at holes K51-K54 are andesite and limestone. Images of the seismic cross-section show that there are fissures at holes K43-K44, and there are also fissures at holes K51-K54. The results revealed by boreholes are consistent with that shown by the seismic image.

In Figure 2, the locations of holes K1-K7, K36-K41, and K44-K55 are the relative deep river channels. At holes K36-K41, because of the fracture zones which are easy to be corroded, the eroding river channel is in the deepest. The buried limestone around holes K7-K36 form the undulating terrain, which should be because that it was exposed to the earth's surface at that time, with the cracks and corrosion developing, the ups and downs of topography formed under the influence of the corrosion, flowing water, etc. There is the development of karst caves and cracks, which is revealed by drilling in the limestone buried at the bottom of river channel. Therefore, parts of the paleo-valley are relatively deep.

The OSL age of the sample collected from the coarse sand and gravel layer which is near the bedrock of the river channel's bottom near the G327 Yihe River Bridge is $22.81 \pm 2.58 \mathrm{ka}$. The ${ }^{14} \mathrm{C}$ dating of the samples collected from the buried paleo-floodplain on the right bank of the Benghe River is $12210+50$ a B.P. on the upper side and 14020+60a B.P. on the lower side. From this, it can be deduced that: in the location of holes K1-K7 in Figure 2, the paleo-valley below $55 \mathrm{~m}$ is the paleo-valley of the Benghe River during the Last Glacial Maximum; in the locations of holes K36-K41 and holes K44-K55, The paleo-valley below $53 \mathrm{~m}$ is considered as the paleo-valley of the Yihe River in the LGM. During the LGM, there was still a 620-meter watershed between the Benghe River and the Yihe River, and the Benghe River had not flowed into the Yihe River yet near the Jiuqu Yihe River Bridge. In Figure 2, the river channel is full of sedimentary tawny coarse sand above approximately 54m; it should be the riverbed deposition since the Late Glacial, demonstrating that the Benghe River infused into the Yihe River at the upstream of the Jiuqu River Bridge after the Late Glacial. Since the Late Glacial, the width-depth ratio of the Yihe River paleo-valley is very big. Due to the big seasonal change of rainfall in the Yihe River's basin, the river forms the bifurcated and braided river feature, when there is scarce water yield in the seasons--winter and spring.

\section{Summary}

In the bottom of the Yihe River paleo-valley, there is the development of fault zones. Between holes K38-K43 is the faulted fracture zone, which is $80 \mathrm{~m}$ in width, trending northwest. There is also crevice between holes K43-K44, and holes K51-K54. 
According to the OSL age $(22.81 \pm 2.58 \mathrm{ka})$ of the sediment in the bottom of riverbed and the ${ }^{14} \mathrm{C}$ age (14020 \pm 60 a B.P.) of the floodplain sediment in burial terrace, it can be inferred that the river channel which is approximately $53 \mathrm{~m}$ to $55 \mathrm{~m}$ below the vicinity of the Jiuqu Yihe River Bridge is the paleo-valley of the Yihe River and the Benghe River in the Last Glacial Maximum and the river channel which is approximately $54 \mathrm{~m}$ above is the paleo-valley of the Yihe River since the Late Glacial. Since the river channel is broad and shallow and the seasonal change in the flow is huge, branching-braid-like characteristics of the river are formed in winters and springs.

During the Last Glacial Maximum, the Benghe River flowed into the Yihe River at the downstream of the Jiuqu Yihe River Bridge; after the Late Glacial, the Benghe River flowed into the Yihe River approximately at the current location where it enters the Yihe River.

This study does not collect many dating samples, which may affect the accuracy of the results to a certain extent. Therefore, the future research on paleochannel should increase sampling points as much as possible and collect more representative dating samples. Furthermore, under the condition of financial resources and technology allow, advanced research tools and methods should be adopted in order to improve the resolution of the research on paleochannel.

\section{Acknowledgement}

This study was supported by the National Natural Science Foundation of China (Grant No. 41372182) and Natural Science Foundation of Shandong Province, China (ZR2012DL02).

First author: Wu Ting (1990- ), Master in reading, specialized in Late Quaternary environmental evolution in the Yangtze River delta.

Corresponding author: Cao Guangjie (1964- ), PhD and Professor, specialized in Late Quaternary environmental evolution in the Yangtze River delta.

\section{References}

[1] C.X. Li and G.J. Zhang, A sea-running Changjiang River during the last glaciation, Acta Geographica Sinica. 1995, 50(5): 459-463.

[2] C.X. Li, P. Wang, H.P. Sun, J.Q. Zhang, D.D. Fan and B. Deng, Late Quaternary incised-valley fill of the Yangtze delta (China): its stratigraphic framework and evolution, Sedimentary Geology. 2002, 152: 133-158.

[3] C.X. Li, P. Li and X.R. Cheng, The influence of marine factors on sedimentary characteristics of Yangtze River channel below Zhenjiang, Acta Geographica Sinica. 1983, 38(2): 128-140.

[4] Y.R. Yuan, The late Pleistocene Changjiang estuary on the outer shell of the East China Sea, Oceanologica Sinica. 1992, 14(6): 85-89.

[5] D.Y. Yang, The paleoenvironment of the mid-lower regions of Changjiang in the full-glacial period of Late Pleistocene, Acta Geographica Sinica. 41(4): 302-310.

[6] Z.X. Liu, S. Berne and the L'ATALANTE Sci-entific Party, Paleochannels and paleodeltas in the continental shelf of the East China Sea, Marine Geology \& Quaternary Geology. 2000, 20(1): 9-14.

[7] G.X. Li, Y. Liu, Z.G. Yang, S.H. Yue, W.D. Yang and X.B. Han, The Yangtze River paleochannel at East China Sea shelf plain during the Last Glacial Period, Science in China, Ser. D(Geoscience). 2005, 35(3): 284-289.

[8] D.X. Xia and Z.X. Liu, Tracing the Changjiang River's flowing route into the sea during the last glacial maximum, Acta Oceanologica Sinica. 2001, 23(5): 87-95.

[9] G.J. Cao and Y.Y. Li, Characteristics of Nanjing paleovalley section of the Yangtze River during the Last Glacial Maximum, Marine Geology \& Quaternary Geology. 2009, 29(3): 39-42. 
[10] G.J. Cao, J. Wang, X.Q. Zhang, G.X. Qu, S.B. Bai and X.H. Gong, Characteristics and run off volume of the Yangtze River paleovalley at Nanjing reach in the Last Glacial Maximum, Geographica Sinica. 2009, 64(3): 331-338.

[11] G.J. Cao, J.B. Cuan and Y.Y. Li, Characteristics of the Yangtze River Paleo-valley in Jiangsu Province in the Last Glacial Maximum, Scientia Geographica Sinica. 2012, 32(8): 986-992.

[12] K. Liu, Z.Y. Zhuang, D.Y. Liu, Y.C. Ye and G.Y. Hu, Study of the buriedancient channels in the continental shelf area out of themouth of the Changjiang River in China, Acta Oceanologica Sinica. 2009, 31(5): 80-88.

[13] Z.L. Zhang, A preliminary study on the paleochannel of the Yellow River in Lubei plain, Acta Geographica Sinica. 2012, 45(4): 457-466.

[14] C. Wu, X.Q. Zhu, N.H. He, et al, A study of the formation of ancient channels on the north China plain, Science in China: Ser. B. 1991, (2): 188-197.

[15] C. Wu, Z.H. Wang and Q.H. Xu, Shallow buried ancient channels of Hebei Plain, Acta Geographica Sinica. 1986, 41(4): 332-340.

[16] Z.G. Huang, W.Q. Zhang and F.X. Cai, The submerged Zhujiang Delta, Acta Geographica Sinica. 1995, 50(3): 206-214.

[17] C.M. Lin, H.C. Zhuo and S. Gao, Sedimentary facies and evolution in the Qiantang River incised valley, eastern China, Marine Geology. 2003, (219): 235-259.

[18] X.L. Fu and R.Q. Li, A preliminary study on the paleochannel of the Huaihe River in the Huainan area, Journal of Beijing NormalUniversity: Natural Science. 1998, 34(2): 276-279. 